\title{
Impregnated Plug Dosage Form
}

National Cancer Institute

\section{Source}

National Cancer Institute. Impregnated Plug Dosage Form. NCI Thesaurus. Code C149572.

Solid preparation consisting of a piece of material (e.g. polyethylene), usually porous, in which a liquid, semi-solid or solid preparation is impregnated. 